\title{
INFLUÊNCIA DA HIDRATAÇÃO E DA ORIENTAÇÃO DE ENFERMAGEM NA OBTENÇÃO DE URINA EM JATO COM ASSEPSIA
}

\author{
Emilia Luigia Saporiti Angerami * \\ Maura Santesso Takakura * \\ Magali Roseira Boemer * \\ Branca Maria de Oliveira *
}

$\mathrm{O}$ ato de urinar envolve fatores fisiológicos, psicológicos e culturais. Os padrões de comportamento que constituem uma cultura específica, segundo Foster,(3) não são determinados genética ou biologicamente. Pelo processo de socialização ou aculturação a criança adquire as atitudes, as formas de comportamento apropriadas. os padrões e valores da sociedade em que nascem.

O começo da socialização da criança se dá, segundo Malpass et alii,(7) entre 12 e 15 meses, quando a maioria das crianças é capaz de falar, andar e iniciar o treinamento das dejeções. Tais atividades são aprendidas quando a criança tem maturidade suficiente e quando existe reforço social.

O treinamento das eliminações envolve a substituição de uma ação reflexa à pressão interna por um controle voluntário da eliminação. A criança é encorajada a controlar a eliminação em vez de comportar-se reflexivamente.

Por isso, o ato de urinar, mesmo sendo de natureza reflexa, se inicia, em condições normais, sob ação de nossa vontade. Quando sobrevém o desejo de urinar, o adulto é capaz de reprimir ou ceder a este desejo obedecendo aos seus padrões culturais.

Ganong(4) diz que é devido à habilidade desenvolvida no sentido de manter o esfíncter externo em estado de permanente contração, que os adultos podem adiar a micção para ocasião oportuna.

* Docentes do Departamento de Enfermagem Geral e Especializada da Escola de Enfermagem de Ribeirão Preto, USP. 
Segundo Houssay,(5) no adulto, esta habilidade se consegue até que a bexiga contenha cerca de $700 \mathrm{ml}$ de urina; em limites superiores a esse, o desejo se torna imperioso e é acompanhado de sensação dolorosa no hipogástrico.

MacClain e Gragg(8) dizem que os pacientes podem reter a urina devido ao constrangimento pela presença de outras pessoas ou por medo.

Quando a colheita de urina requer a presença de uma profissional devido a aspectos técnicos da colheita, dois fatores devem ser levados em consideração: o fato de urinar na presença de outra pessoa - ato reprimido pela nossa cultura - e o medo do exame.

Em "Anxiety",(2) encontramos que a ansiedade se desenvolve em 3 fases: ameaça à própria imagem, ansiedade apresentando reações fisiológicas e mentais e mudança de comportamento. Neste trabalho, os autores referem que é difícil definir a natureza exata da ansiedade e expor os fatores que nela interagem, mas que é fácil reconhecer suas manifestações, ou seja, os meios pelas quais ela se revela; algumas vezes a experiência de ansiedade é acompanhada de modificações da conduta.

$\mathrm{O}$ síndrome de ativação, que aparece no medo, na rajva e na ansiedade, segundo Skinner,(9) caracteriza-se pelo aumento das pulsações, da inspiração e da sudorese, sendo prejudicial nas moléstias psico-somáticas. Refere ainda, que estados emocionais podem ocorrer quando não se recebe reforço costumeiro. Por isso, afirma que antes de se tentar um condicionamento e uma resposta, deve-se permitir uma adaptação ao ambiente e à remoção de estímulos aversivos. A ansiedade é considerada por ele mais aversiva que reforçadora. Por isso, pressupõe que uma pessoa ansiosa está num estado emocional aversivo, o que modificará seu comportamento.

Em trabalho anterior,(1) os autores, estudando a técnica de colheita de urina com assepsia, notaram que algumas pacientes quando solicitadas a urinar não o conseguiam, o que os levou à hipótese de que dois fatores poderiam estar presentes: quantidade insuficiente de urina na bexiga, não provocando a sensação de urgência, ou um estado de ansiedade, impedindo a paciente de responder à sclicitação.

Em vista do exposto, pensamos com este trabalho, interagir com dois grupos de pacientes e, posteriormente, comparar os resultados a um grupo controle.

* Jato satisfatório - é a micçấo espontânea obtida quando a paciente urina deitada ou semi-deitada conforme a técnica descrita (Angerami e col. (1) . 
Em um grupo experimental, estudaríamos a influência da hidratação, proporcionando maior quantidade de líquido na bexiga; num outro, a paciente receberia, através de uma entrevista, toda a orientação sobre o exame e esclarecimento que desejasse, numa tentativa de eliminar eventuais tensões e comportamentos aversivos. Com o grupo controle seguiríamos a rotina hospitalar.

\section{OBJETIVOS}

1. Estudar a obtenção de jatos satisfatórios* em mulheres submetidas a prévia hidratação;

2. Estudar a obtenção de jatos satisfatórios em mulheres submetidas a orientação prévia sobre o exame.

\section{MATERIAL E MÉTODOS}

\section{População:}

Pacientes adultos, do sexo feminino, que procuram o ambulatório do Hospital das Clínicas da Faculdade de Medicina de Ribeirão Preto, para colheita de urina, com técnica asséptica.

Critério de Exclusão:

- Foram excluídas as pacientes menores de 15 anos, menstruadas, com problemas neurológicos ou psíquicos aparentes, e que já haviam participado do presente trabalho.

\section{Metodologia}

As autoras do estudo, enfermeiras, foram responsáveis pelas várias etapas da pesquisa a saber: exclusão, prévia orientação, hidratação das pacientes e colheita das amostras.

Duas enfermeiras encarregaram-se da seleção e encaminhamento das pacientes para um dos três grupos de trabalho, num total de 50 pacientee para cada grupo. Esse encaminhamento foi estabelecido por sorteio, no primeiro dia do trabalho, cuja seqüência foi mantida.

Cada paciente, por ordem de chegada, foi designada para o grupo ao qual pertencia, assim sendo:

\section{Grupo 0 - Prévia Orientação}

Foi feita a identificação da paciente que constou de: nome, registro, procedência, idade. 
A prévia orientação foi dividida em duas etapas: numa entrevista inicial fez-se uma observação para verificar se a paciente apresentava sinais e sintomas de ansiedade. Identificamos: freqüência de pulso e respiração; caracierísticas da respiração; condições da pele (úmida, fria, cor, sudorese); repetição de palavras e/ou orações; gagueiras; comportamento motor (movimentação das mãos, tremor, irriquieta na cadeira; outros comportamentos tais como mexer com os olhos, cabelos, roupa). Perguntamos se estava preocupada com o exame, qual o horário da última micção e se estava em jejum hídrico. Solicitamos, finalmente, a descrição da experiência anterior durante a colheita de urina.

$\mathrm{Na}$ segunda etapa, para esclarecimento do paciente, mostramos um cartaz dos órgãos genitais femininos externos. Ao mesmo tempo, fazíamos uma descrição simples da anatomia e fisiologia e sua importância na aplicação da técnica.

Outras dúvidas que a paciente apresentasse foram esclarecidas e ressaltamos a importância de sua colaboração.

\section{Grupo $H$ - Hidratação Prévia}

Foi feita identificação da paciente: nome, registro, procedência, idade.

Foram anotados: horário da última micção, jejum hídrico, experiência anterior em colheita de urina.

A seguir, ministramos $250 \mathrm{ml}$ de água e anotamos o horário da ingestão, solicitando a paciente que esperasse ser chamada. $O$ intervalo entre a ingestão e a chamada foi de um mínimo de 30 minutos.

\section{Grupo C - Grupo Controle}

Este grupo era apenas triado e encaminhado para a colheita sem nenhum tratamento prévio.

A chamada para o exame foi feita pela enfermeira responsável pela colheita, que desconhecendo a qual grupo pertencia a paciente, colhia as amostras de acordo com a técnica já descrita em trabalho anterior.

Após a obtenção da amostra, um questionário comum aos 3 grupos completava e checava as informações desejadas.

Este questionário consistia da identificação da paciente: nome, registro, idade e procedência; experiência anterior em colheita de urina; horário da última micção; jejum hídrico; posição habitual para urinar; como se sentiu durante o exame; se achou difícil urinar e porque; posição utilizada para colheita (deitada, sentada na mesa, de cócoras). 


\section{RESULTADOS E DISCUSSÃO}

Foram colhidas 150 amostras de urina de pacientes que procuraram o ambulatório do Hospital das Clínicas da Faculdade de Medicina de Ribeirão Preto e que satisfizeram o critéria de inclusão descrito anteriormente.

A idade das pacientes variou entre 15-65 anos, sendo que nos três grupos a maior freqüência concentrou-se na faixa etária de 35-55 anos.

Observamos que nos grupos tratados, hidratação e orientação, obtivemos melhor resultado, provando que a assistência de enfermagem reflete nos resultados desejados, pois verificamos que $74 \%$ das pacientes do Grupo 0 e $78 \%$ das do grupo $\mathrm{H}$ conseguiram uma colheita satisfatória, contra $54 \%$ do grupo controle.

Lima et alii(6) referem-se à necessidade de ser a primeira micção da manhã a utilizada para exame bacteriológico. Observamos este aspecto no nosso grupo de pacientes, usando a variável tempo de enchimento de bexiga (obtido pela diferença entre horário da última micção informada pela paciente e o horário da colheita) que foi analizada pela distribuição em quartis, com os seguintes resultados:

Total de tempo de enchimento da bexiga nos três grupos:

$Q_{1} 131 \mathrm{~min} \quad Q_{3} \quad 244 \mathrm{~min}$ Mi $189 \mathrm{~min} \quad \mathrm{Q}=57 \mathrm{~T}=0$

Total do tempo de enchimento de bexiga, com jatos satisfatórios nos três grupos:

$\mathrm{Q}_{1} 134 \mathrm{~min} \quad \mathrm{Q}_{3} 243 \mathrm{~min} \quad \mathrm{Mi} 192 \mathrm{~min} \quad \mathrm{Q}=58 \mathrm{~T}=0,017$

Total do tempo de enchimento de bexiga, com jatos não satisfatórios, nos três grupos:

$\mathrm{Q}_{1} 117 \mathrm{~min} \quad \mathrm{Q}_{3} 236 \mathrm{~min} \quad \mathrm{Mi} 180 \mathrm{~min} \quad \mathrm{Q}=60 \mathrm{~T}=0,058$

Desta distribuição, podemos observar que $50 \%$ das pacientes que vem para o exame, estão sem urinar há um período de tempo entre 131 e $244 \mathrm{~min}, 25 \%$ estão abaixo e $25 \%$ estão acima destes limites, havendo uma perfeita simetria em torno da mediana.

Se levarmos em consideração que a paciente deveria ser orientada quanto ao tipo de exame que iria realizar, quanto à importância de ter uma bexiga cheia para uma melhor resposta ao exame, era de se esperar uma curva com franca assimetria à direita.

Se analisarmos os resultados dos jatos satisfatórios, verificamos que $50 \%$ das respostas positivas estão no horário compreendido entre 134 minutos e 243 minutos, $25 \%$ estão abaixo e $25 \%$, acima. A curva mostra uma ligeira assimetria à direita ou negativa. 
Considerando esses resultados, podemos sugerir que a orientação dada às pacientes, quando da solicitação do exame, seja no sentido de um tempo de enchimento de bexiga de no mínimo 4 horas. Isto é importante se lembrarmos o problema de desconforto sentido e relatado pelas pacientes que necessitam viajar, provenientes de outras cidades ou moradoras distantes do hospital.

Outra orientação a ser dada deveria ser quanto à hidratação, pois verificamos que as pacientes que não estavam em jejum hídrico tiveram melhores resultados na colheita. No grupo hidratação, houve uma porcentagem de $94 \%$ de jatos satisfatórios, nas pacientes que não estavam em jejum, isto pode assumir maior relevância se considerarmos os $250 \mathrm{ml}$ de água ministrados.

Ressaltamos, ainda, a necessidade de prévia orientação pois, no grupo selecionado para uma orientação planejada, detectamos em 21 pacientes, diferentes sinais e sintomas de ansiedade. Destas, apenas $4(20 \%)$ não urinaram; as demais parecem ter respondido ao tratamento. Das que não apresentavam sinais e sintomas de ansiedade, $68 \%$ urinaram e $32 \%$ não.

Quando inquerimos as pacientes deste grupo quanto à preocupação em relação ao exame, apenas 14 afirmaram estar preocupadas, mostrando que nem sempre a paciente diz o que está sentindo. Neste grupo, $9(64 \%)$ urinaram e $5(36 \%)$ não, o que nos leva a crer que a orientação ajudou a paciente durante o exame.

Todas as orientações, entretanto, devem ser iniciadas no momento do pedido de exame, para que a paciente possa vir para a colheita preenchendo todos os requisitos por nós analisados. Ao chegar ao hospital, a paciente deve ser hidratada, e a pessoa responsáver reforçará as informações anteriores.

As maiores dificuldades referidas pelas pacientes em relação ao exame foram: posição para colheita, não hábito em urinar deitada, vergonha e "nervoso", isto vem de encontro à opinião dos diferent.es autores citados na introdução do trabalho $(2,3,7)$, a respeito da micção. São fatores muito importantes que não devem ser esquecidos pelo pessoal de enfermagem, quando da assistência à paciente pois, embora todas tivessem se referido às mesmas dificuldades, as do Grupo 0 foram as que informaram terem se sentido melhor durante o exame.

A experiência anterior (qualquer forma de colheita de urina para exame bacteriológico, cateterismo vesical, assepsia dos genitais ou outros) poderia ter influência negativa ou positiva no comportamento das pacientes, facilitando ou dificultando o exame.

$O$ resultado da experiência anterior nos grupos 0 e $\mathrm{H}$ são semelhantes com pequena vantagem para o grupo sem experiência anterior. No grupo controle ocorre o inverso, isto é, o grupo com ex- 
periência anterior teve maior número de jatos satisfatórios. Isto nos ieva a crer que o que interferiu nos grupos $0 \mathrm{e} \mathrm{H}$ foram os tratamentos dados e não a experiência anterior. Assim, no grupo 0 , ao explicarmos à paciente como seria o exame e solicitarmos a sua colaboração, sentimos ter anulado os fatores negativos existentes (grupo de pacientes com experiência prévia) e dado informações corretas (novo grupo).

O grupo $\mathrm{H}$ recebeu um interferência fisiológica, pois através da hidratação contribuímos para o aumento da diurese; aumentando o liquido contido na bexiga, elevou-se a pressão intra-vesical e, conseqüentemente, intensificou-se o desejo de urinar.

No grupo controle, as respostas são fruto da própria experiência, pois o maior número de jatos não satisfatórios está neste grupo, inexperiente e sem nenhum tratamento.

Se a enfermeira interagir com o paciente, obterá melhores resultados na assistência de enfermagem, como provam estes resultados.

\section{CONCLUSÕES}

1. Os grupos tratados pela hidratação ou orientação prévia obtiveram maior porcentagem ( $\mathbf{7 8 \%}$ e $\mathbf{7 4 \%}$ respectivamente) de jatos satisfatórios do que o grupo controle $(54 \%)$.

2. As pacientes precisam ser orientadas com antecedência quanto: ao tempo mínimo de enchimento de bexiga; a não obrigatoriedade de jejum; a técnica de colheita do exame.

3. A paciente orientada sente-se mais tranqüila durante o exame e conseqüentemente melhor colaboração é dada.

4. O maior número de jatos satisfatórios está nos grupos de pacientes sem experiência anterior e que receberam tratamento.

5. Esses resultados nos levam ainda a inferir que, se na prática, os dois tratamentos forem associados, melhores resultados serão obtidos.

$\mathrm{Na}$ ação de enfermagem, que nos propusemos a estudar, comprovamos que, para a realização de um procedimento de enfermagem é necessário preparar o paciente nos aspectos bio-psico-sociais

\section{REFERENCIAS BIBLIOGRAFICAS}

1. ANGERAMI, E.L.S. et alii - Avaliação da técnica de colheita de urina asséptica em mulheres. Apresentado no XXV Congresso Brasileiro de Enfermagem, João Pessoa, 15 a 21 de julho, 1973. 
2. ANXIETY: recognition and intervention. Amer. J. Nurs. 65: 129-152, Sept., 1965.

3. FOSTER, George M. - O contexto cultural do desenvolvimento tecnológico. In: - As culturas tradicionais e o impacto da tecnologia. Rio de Janeiro, Editora Fundo de Cultura, 1962, Cap. I, p. 20-23.

4. GANONG, William F. - Micção. In: - Fisiologia médica. São Paulo, Atheneu Editora, 1972. Cap. 8, p. 582-583.

5. HOUSSAY, Bernardo A. et alii Formacion y excrecion de la orina: In: Fisiologia humana. Buenos Aires, El Ateneo, 1972, Cap. 8, p. 879-917.

6. LIMA, A. Oliveira et alii Exame de urina. In: - Métodos de laboratório aplicados a clínica. Rio de Janeiro, Guanabara, Koogan, 1969, Cap. 4, p. 122-149.

7. MALPASS, Leslie F. et alii O comportamento humano: um programa para auto-aprendizagem. Rio de Janeiro, Editora Renes, 1969.

8. MCCLAIN, M.E. \& GRAGG, S.H. - Eliminação e tratamento àa bexiga. In: - Principios científicos da enfermagem. Rio de Janeiro, Ed. Científica, 1970. Cap. 17, p. 246-261.

9. HOLLAND, J.G. \& SKINNER, B.F. - Experimentos de ansiedade. In: $-A$ análise do comportamento. Trad. e adaptação Rodolpho Azzi. São Paulo, Herder, Ed. U.S.P., 1969, p. 236-243. 